\title{
Fibroblast Growth Factor 8 Regulates Neocortical Guidance of Area-Specific Thalamic Innervation
}

\author{
Tomomi Shimogori and Elizabeth A. Grove \\ Department of Neurobiology, Pharmacology, and Physiology, University of Chicago, Chicago, Illinois 60637
}

\begin{abstract}
Thalamic innervation of each neocortical area is vital to cortical function, but the developmental strategies that guide axons to specific areas remain unclear. We took a new approach to determine the contribution of intracortical cues. The cortical patterning molecule fibroblast growth factor 8 (FGF8) was misexpressed in the cortical primordium to rearrange the area map. Thalamic axons faithfully tracked changes in area position and innervated duplicated somatosensory barrel fields induced by an ectopic source of FGF8, indicating that thalamic axons indeed use intracortical positional information. Because cortical layers are generated in temporal order, FGF8 misexpression at different ages could be used to shift regional identity in the subplate and cortical plate either in or out of register. Thalamic axons showed strikingly different responses in the two different conditions, disclosing sources of positional guidance in both subplate and cortical plate. Unexpectedly, axon trajectories indicated that an individual neocortical layer could provide not only laminar but also area-specific guidance. Our findings demonstrate that thalamocortical axons are directed by sequential, positional cues within the cortex and implicate FGF8 as an indirect regulator of thalamocortical innervation.
\end{abstract}

Key words: FGF8; neocortex; area map; thalamus; axon guidance; electroporation

\section{Introduction}

Each neocortical area is characterized by a particular pattern of innervation from the thalamus. The functional specialization of each area depends on this input, as does the development of areaspecific functional architecture (Rakic, 1988; Sur et al., 1988; Erzurumlu and Jhaveri, 1990; Sur et al., 1990; Rakic et al., 1991; Iwasato et al., 2000; Sharma et al., 2000; Guillery and Sherman, 2002; Kahn and Krubitzer, 2002; Sherman and Guillery, 2002). How thalamocortical innervation is set up in development remains a focus of concentrated investigation (Garel et al., 2002; Hevner et al., 2002; Lopez-Bendito et al., 2002; Dufour et al., 2003; Seibt et al., 2003; Garel and Rubenstein, 2004).

It is clear, however, that, for proper function, thalamocortical innervation and the cortical area map must be in register. Recent studies support a classic proposal (Rakic, 1988) that the neocortical area map is set up by mechanisms inside the cortical primordium (Rakic, 1988; Donoghue and Rakic, 1999a,b; Miyashita-Lin et al., 1999; Bishop et al., 2000, 2002, 2003; Mallamaci et al., 2000; Fukuchi-Shimogori and Grove, 2001, 2003; Nakagawa and O'Leary, 2001; Muzio et al., 2002; Garel et al., 2003; Yun et al., 2003; Hamasaki et al., 2004; Huffman et al., 2004). Positional identity in the neocortex is partly independent of and precedes thalamic innervation, suggesting that intracortical guidance cues could direct thalamic input.

Received Feb. 2, 2005; revised May 9, 2005; accepted May 12, 2005.

This work was supported by National Institutes of Health Grant R01HD42330 and the March of Dimes Birth Defects Foundation. We thank J. Naegele, C. Ragsdale, H. Ng, and V. Bindokas for discussion and technical help and M. Donoghue, M. J. Hayman, and A. Rattner for CDNAs.

Correspondence should be addressed to E. A. Grove, Department of Neurobiology, Pharmacology, and Physiology, MC0926, University of Chicago, Chicago, IL 60637. E-mail: egrove@drugs.bsd.uchicago.edu.

DOI:10.1523/JNEUROSCI.0453-05.2005

Copyright $\odot 2005$ Society for Neuroscience $\quad$ 0270-6474/05/256550-11\$15.00/0
Mechanisms that pattern the neocortical area map include signaling from an anterior telencephalic source of fibroblast growth factor (FGF) 8 and the activity levels of the transcription factor Emx2 (Bishop et al., 2000, 2002, 2003; Mallamaci et al., 2000; Fukuchi-Shimogori and Grove, 2001; Muzio et al., 2002; Fukuchi-Shimogori and Grove, 2003; Garel et al., 2003; Hamasaki et al., 2004; Huffman et al., 2004). FGF8 and Emx2 interact by each regulating the expression of the other (FukuchiShimogori and Grove, 2003; Garel et al., 2003). These early patterning events set into motion a developmental cascade that leads to the differentiation of area-specific features (FukuchiShimogori and Grove, 2001; Hamasaki et al., 2004; Huffman et al., 2004), strikingly including intra-neocortical projections (Huffman et al., 2004).

Although not yet directly tested, it is highly likely that a major feature regulated by FGF signaling is area-specific thalamic innervation. For example, changes in FGF8/17 signaling in the mouse cortical primordium can shift the whisker barrel fields of primary somatosensory cortex (S1) in either direction along the anterior-to-posterior (A/P) cortical axis or even partially duplicate fields (Fukuchi-Shimogori and Grove, 2001, 2003). Similarly, when the transcription factor Emx2 is overexpressed in the cortical neuroephithelium by transgenesis, the barrel fields shift anteriorly in the neocortical map (Hamasaki et al., 2004). Ectopic barrels are almost certainly innervated by the somatosensory thalamus, given that, in normal development, formation and early maintenance of barrels depend on functional connectivity (Woolsey and Van der Loos, 1970; Van der Loos and Woolsey, 1973; Jeanmonod et al., 1981).

Together, these findings prompt the hypothesis that early patterning events provide positional information to the cortical primordium and thereby influence the distribution of molecular 
axon guidance cues. After thalamic axons have arrived beneath the cortex, these intracortical cues direct area-specific input. To test this possibility, we rearranged the neocortical area map by altering FGF8 signaling in the cortical primordium, using electroporation-mediated gene transfer.

\section{Materials and Methods}

Animals. CD-1 or R26R mice (The Jackson Laboratory, Bar Harbor, ME) were used in compliance with National Institutes of Health guidelines, and with approval of the University of Chicago Institutional Animal Care and Use Committee. For timed pregnancies, noon of the day on which a vaginal plug was detected was considered E0.5.

In utero electroporation. The abdomen was surgically opened in timedpregnant mice, without opening the uterus itself. Embryos at E10.5E12.5 were viewed with a fiber optic light source through the uterine wall. Expression plasmids, carrying Fgf8, sFgfr $3 c$ (encoding a soluble, truncated form of FGF receptor 3c, a high-affinity receptor for FGF8), Cre recombinase, or human placental alkaline phosphatase $(A P)$ as a control (Fukuchi-Shimogori and Grove, 2001, 2003), were injected into one cerebral vesicle of each embryo. Fine tungsten and platinum electrodes were positioned inside the uterus, on either side of the tissue to be transfected. Electroporation was directed either anteriorly or posteriorly in the dorsal cerebrum. In the former case, both electrodes were positioned in the telencephalic vesicles; in the latter, the negative electrode was outside the brain. After electroporation, embryos were allowed to develop in utero with $60 \%$ survival beyond birth.

In most experiments described here, brains were harvested at postnatal day 0 (P0) to $\mathrm{P} 1$ or at $\mathrm{P} 5-\mathrm{P} 6$ and fixed by transcardial perfusion with $4 \%$ paraformaldehyde (PFA). After this 1-2 week delay, transgene expression is no longer seen with our method of electroporation. In experiments performed in parallel, transgene expression was tested $2 \mathrm{~d}$ after electroporation. Findings confirmed that efficient electroporation, directed to the anterior pole of the telencephalon, occurs in 50\% of surviving mouse embryos (Fukuchi-Shimogori and Grove, 2001, 2003). Consistent with this, when brains were examined at P1 or P5 after anterior electroporation of $F g f 8$ or $s F g f r 3 c$, appropriately directed shifts were seen in gene expression domains and $S 1$ in $\sim 50 \%$ of surviving mouse pups.

Histology. Section in situ hybridization followed described procedures (Grove et al., 1998), as did cytochrome oxidase (CO), 5-bromo-4chloro-3-indolyl- $\beta$-D-galactopyranoside (X-gal), and AP histochemistry (Fukuchi-Shimogori and Grove, 2001, 2003). Immunochemical localization of 5-HT transporter (5-HTT) and growth associated protein 43 (GAP43) used, respectively, primary antibodies 849-6 (diluted 1:500; DiaSorin, Stillwater, MN) and G9624 (diluted 1:15,000; Sigma, St. Louis, MO).

Labeling thalamocortical projections from the thalamus. Postnatal brains were harvested and fixed, and a crystal of the fluorescent carbocyanide dye 1,1'-dioctadecyl 3,3,3',3'-tetramethylindocarbocyanine perchlorate (DiI) Molecular Probes, Eugene, OR) was positioned in the somatosensory, ventrobasal nuclei of the thalamus (VB), with the aid of a dissection scope equipped for fluorescence (Leica, Nussloch, Germany).

After incubation for $2-4$ weeks at $37^{\circ} \mathrm{C}$ in $4 \%$ PFA, distinctive S1 barrels labeled with DiI could be seen in the intact forebrain, thus allowing selection for additional processing of those brains in which DiI had been accurately deposited in the VB. Brains were vibratome sectioned, examined with an Axoskop microscope, and photographed with a digital camera using Axiocam software (Zeiss). The site of the DiI deposit in the VB thalamus was confirmed in Nissl-stained sections.

Selection of brains for analysis. For thalamocortical tracing experiments, 14 Fgf8-electroporated, postnatal brains were selected for additional analysis based on apparent shifts or partial duplications in S1, visible by DiI fluorescence in intact brains. Duplications only appeared in brains in which Fgf8 electroporation had been directed to the posterior pole of the hemisphere. Similarly, posterior shifts in S1 were evident only when $F g f 8$ electroporation was aimed at the anterior pole. In the control brains selected, S1 was visible by DiI labeling, but no shifts or duplica- tions appeared. Brains with too little DiI labeling, or labeling elsewhere, were not further analyzed.

The number of selected brains compared with the total number of available brains reflects the practical success of several experimental steps: efficient electroporation, accurate placement of DiI into the VB, and effective diffusion of DiI to the cortex (which, in the myelinating P5-P6 brains, was not completely reliable). After photographing DiIlabeled axonal trajectories, sections from all brains were Nissl stained (see Fig. $6 D$ ). In all cases, histology showed the same barrel shifts and duplications that had been indicated by DiI labeling. Control brains showed a normally positioned S1 in Nissl-stained sections and no evidence of barrel duplication.

Labeling thalamocortical projections from the cortex. Crystals of DiI or 4-4-dihexadecyl aminostyryl $\mathrm{N}$-methyl-pyridinium iodide (DiA) (Molecular Probes) were placed in two locations in the neocortical primordium. After incubation and processing as above, the distribution of label in different thalamic nuclei was compared between control brains and those with cortical regional shifts.

Cre-lox recombination and $R 26 R$ reporter mice. To follow the fate of transfected cells and their progeny, Cre-lox recombination and R26R reporter mice were used (Fukuchi-Shimogori and Grove, 2003). R26R mice carry lac $Z$ encoding $\beta$-galactosidase ( $\beta$-gal) at the Rosa26 locus, but $\beta$-gal is not produced until a sequence upstream of lac $Z$, containing stop codons and surrounded by loxP sites, is removed by Cre-mediated recombination (Soriano, 1999). Subsequently, those cells in which recombination occurred, together with their progeny, are permanently labeled by production of $\beta$-gal. In the present study, the Cre recombinase gene (Cre) was introduced into the telencephalon of R26R embryos via microelectroporation. Brains were harvested at a range of ages, depending on the specific experiment, and stained with an X-gal procedure (see above) that turns $\beta$-gal-expressing cells blue.

Identifying spread of transfection outside the dorsal telencephalon. A concern in this study was that the thalamus or ventral telencephalon might be inadvertently transfected, potentially allowing FGF8 manipulations to affect other known sites of thalamocortical axon guidance. The high efficiency and accuracy of microelectroporation regionally directed to the anterodorsal telencephalon has been assessed previously in several hundred embryos (Fukuchi-Shimogori and Grove, 2001, 2003). Here we reanalyzed 50 embryos, 2-5 d after microelectroporation had been directed to the anterodorsal telencephalon, and found four with additional transgene expression elsewhere in the forebrain, only one of which included dorsal thalamus. It appeared that to transfect thalamus, microelectrodes must be placed specifically to direct electroporation there. As a second way to identify sites of electroporation, R26R embryos were electroporated with $\mathrm{Cre}$ and analyzed $2 \mathrm{~d}$ later or at postnatal ages when individual thalamic nuclei can be identified. Blue, $\beta$-gal-expressing cells were seen in the embryonic or postnatal neocortex and hippocampus but not in thalamus (supplemental Fig. 1, available at www.jneurosci.org as supplemental material). Finally, FGF8 manipulations did not alter the initial trajectory of axons from the thalamus (see Results), further indicating that no subcortical site of guidance cues was inadvertently affected.

\section{Results}

To shift or duplicate areas, expression plasmids carrying $F g f 8$, $s F g f r 3 c$, encoding a truncated, soluble FGF8 receptor, or $A P$ as a control were microelectroporated into the anterior telencephalon of mouse embryos at E10.5 or E11.5 (Fgf8, sFgfr $3 c$, and $A P$ ) or into the posterior telencephalon at E10.5 ( Fgf8 and AP). Electroporation was regionally directed by positioning the microelectrodes under visual control. Several approaches confirmed that the electroporation site was confined to dorsal telencephalon and did not encroach on the thalamus or any other structure (see Materials and Methods) (supplemental Fig. 1, available at www. jneurosci.org as supplemental material). We therefore presume that the primary effects of FGF8 manipulations were confined to the cortical primordium.

Observations cited above support the somatosensory barrel 
fields of S1 as a focus for investigating the rerouting of thalamic axons. Electroporated brains were therefore harvested at $\mathrm{P} 0-\mathrm{P} 1$, when thalamic axons have grown into the cortex, or at P5-P6, when the barrel fields have formed. As observed previously (Fukuchi-Shimogori and Grove, 2001), excess anterior FGF8 shifted S1 posteriorly, reduction of anterior FGF8/ 17, using electroporated $s F g f r 3 c$, shifted S1 anteriorly, and introducing a second, posterior source of FGF8 duplicated a portion of the S1 barrel fields. Specifically duplicated was all or part of the posteromedial somatosensory barrel field, which represents the five rows of large whiskers on the animal's face, and is abbreviated here as the "whisker pad" (Wp) barrel subfield.

\section{Positional information in the cortex} directs thalamic innervation

To analyze the distribution of axons from the somatosensory ventrobasal thalamus in rearranged maps, tangential sections through layer IV of electroporated P5-P6 cortices were immunohistochemically stained for 5-HTT and GAP43. The latter appear transiently after birth in the axons of sensory thalamic nuclei, including VB (Erzurumlu et al., 1990; Maier et al., 1999; Zhou et al., 2000). Shifted S1 barrel fields labeled for both neurochemical markers (Fig. $1 A-C, E-G, I-K$ ) and additionally displayed a typical barrel histology (Fig. $1 D, H, L)$ that requires NMDA-mediated thalamocortical activity (Iwasato et al., 2000). Duplicated barrels were also identifiable in sections through layer IV by immunoreactivity for 5-HTT and GAP43 (Fig. $1 N-P$ ) and by barrel morphology (data not shown).

Shifts in S1 were seen in the expected $50 \%$ of brains ( $n=26$ brains electroporated anteriorly with $\mathrm{Fg} f 8$ or $s \mathrm{Fg} f \mathrm{r} 3 \mathrm{c}$; a similar number showing no shifts). Duplicate barrels were seen more rarely because of the difficulty of placing microelectrodes for posterior electroporation (see Materials and Methods). Barrels could be distinguished in unstained sections, however, and, whenever duplicates were detected, histology and immunostaining indicated duplicate thalamic innervation. These observations are highly suggestive of repositioned, functionally active thalamic innervation, even in the extraordinary case in which a new FGF8 source generates partial duplicate areas (Fukuchi-Shimogori and Grove, 2001).

\section{Intracortical positional information is both global and graded}

An additional question is whether thalamic axons are instructed simply to respect area boundaries or transitions or whether positional values intrinsic to the cortex define more precisely the territory that axons innervate. Observations of the shape and size of barrels in shifted S1 support the second alternative. When the anterior source of FGF8 was reduced, the entire Wp subfield was
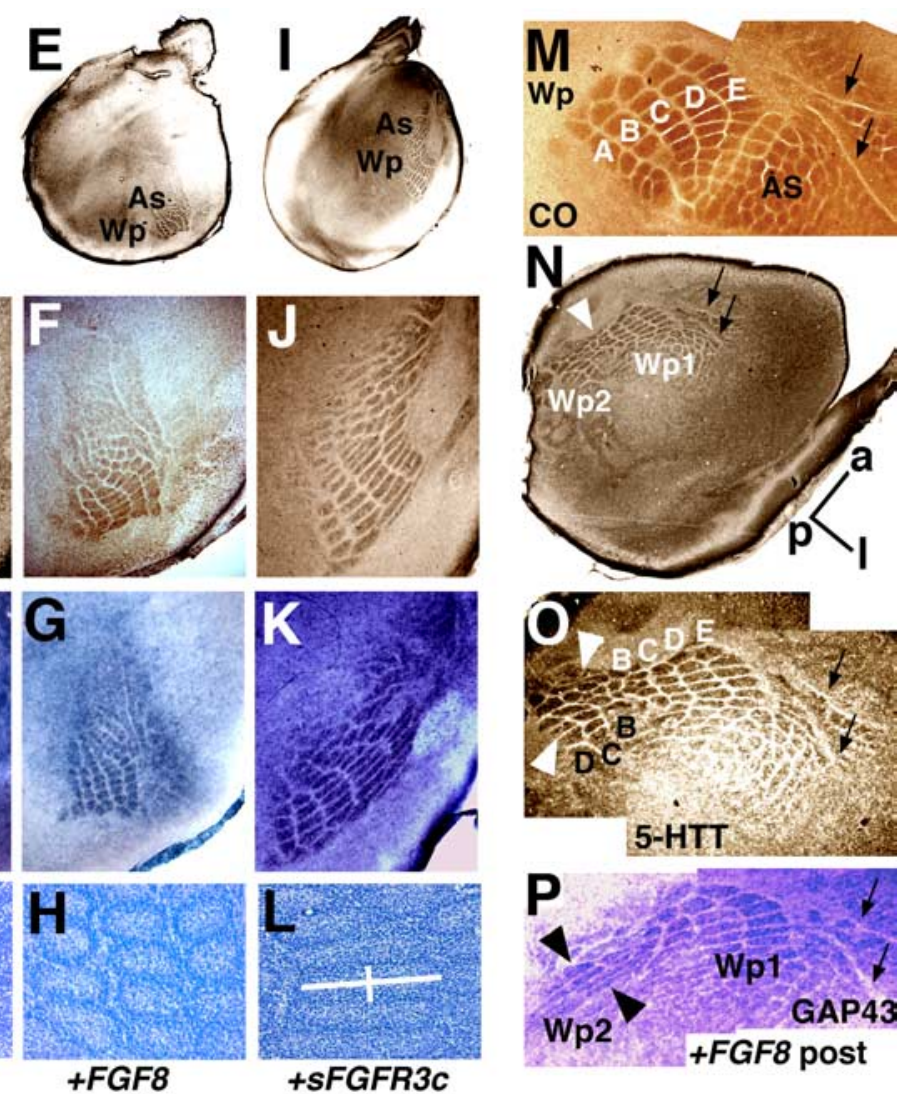

Figure 1. Thalamic innervation is histochemically labeled in shifted and duplicated $\mathrm{S} 1$ barrels. $\boldsymbol{A}-\boldsymbol{P}$, Tangential sections through layer IV of flattened cortices processed for Nissl $(\boldsymbol{D}, \boldsymbol{H}, \boldsymbol{L})$, CO histochemistry $(\boldsymbol{M})$, or 5-HTT (brown) or GAP43 (blue) mmunoreactivity. Both 5-HTT and GAP43 immunoreactivity transiently mark VB axons. $\boldsymbol{B}, \boldsymbol{F}, \boldsymbol{J}$, and $\mathbf{O}$ are higher-magnification (N-P) and perfused at P6.M, CO activity marks individual barrels in layer IV of a control S1. Wp barrel rows A-E are indicated $(n=3)$ are also $G A P 43$ immunoreactive $(\boldsymbol{C}, \boldsymbol{G}, \boldsymbol{K}, \boldsymbol{P})$. In layer IV of a control S1, cell-rich barrel walls surround cell-poor hollows $(\boldsymbol{D})$; brains electroporated with sFgfr3, elongation of individual barrels increases in the $(-$ E rows of Wp (compare $\boldsymbol{B}-\boldsymbol{D}, \boldsymbol{J}-\boldsymbol{L}$ ). Crossed white lines $(\boldsymbol{D}, \boldsymbol{L})$ indicate axes measured to quantify this effect. Scale bar (in $\boldsymbol{D}): \boldsymbol{A}, \boldsymbol{D}, \boldsymbol{E}, \boldsymbol{H}, \boldsymbol{I}, \boldsymbol{L}, 2.0 \mathrm{~mm} ; \boldsymbol{B}, \boldsymbol{C}, \boldsymbol{F}, \boldsymbol{G}, \boldsymbol{J}, \boldsymbol{K}, \boldsymbol{M}, \boldsymbol{O}, \boldsymbol{P}, 0.7$ $\mathrm{mm} ; \boldsymbol{N}, 1.2 \mathrm{~mm}$. As, Anterior snout subfield.

stretched anteriorly, in some cases resulting in a reversal of the curvature of the most anterior, $\mathrm{D}$ and $\mathrm{E}$, rows (Fig. $1 \mathrm{~J}$ ). Individual Wp barrels appeared thinner, "stretched" along the $\mathrm{A} / \mathrm{P}$ axis $(n>$ 10 brains) (Fig. $1 B-D, J-L)$, and these effects increased in the more anterior rows of Wp (Fig. $1 B, D, J, L$ ). Excess anterior FGF8 had the opposite result, compressing the barrels ( $n>10$ brains).

Qualitatively, the shape changes observed were consistent. Individual barrel changes appeared in all brains with shifted barrel fields, and the direction of shape change was strictly dependant on whether the shift was anterior or posterior. No obvious differences in barrel shape were seen between nonelectroporated brains and brains electroporated with the control construct $A P$ $(n>10)$ or with another developmental control gene, Wnt3a $(n=5)$ (Fig. $1 A-D$, and data not shown).

We quantified the shape change, comparing brains with anteriorly shifted barrel fields with control brains. Barrels of row $\mathrm{C}$, the central row in the Wp subfield, were selected. The more anterior rows of the Wp subfield appear more affected (Fig. 1), and 

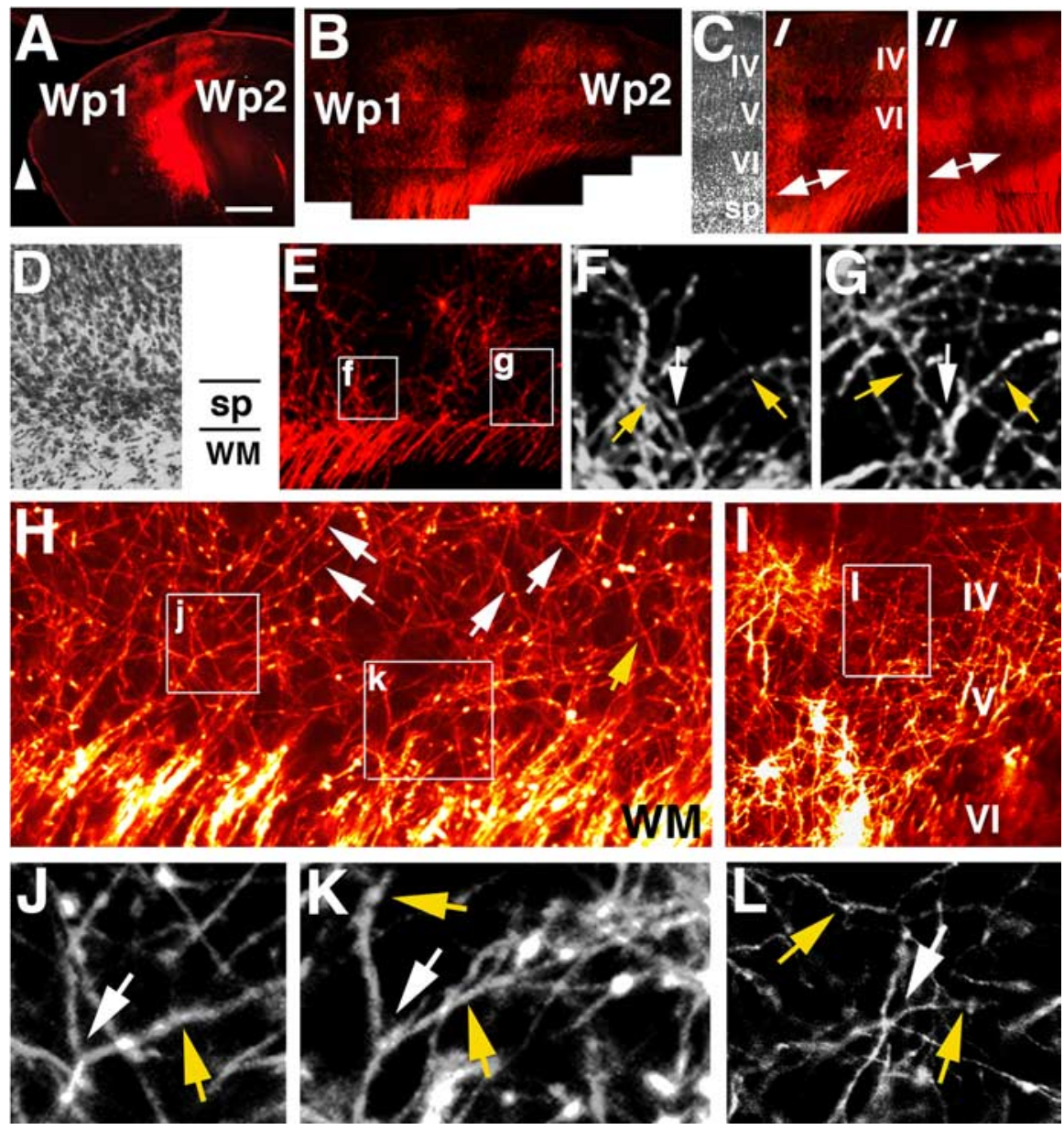

Figure 2. VB axons branch within the cortex to innervate duplicate barrel fields. $\boldsymbol{A}-\boldsymbol{L}$, Sagittal sections at P5 through three cortices with barrel field duplicates. $\boldsymbol{C}$ and $\boldsymbol{D}$ are Nissl-stained sections, serial to $\boldsymbol{C}^{\prime}$ and $\boldsymbol{E}$, respectively; these indicate the location of layers, including the former subplate, layer Vlb (sp/VIb). Other panels illustrate axons labeled by Dil deposits in the VB. $A-C, C^{\prime}$, $C^{\prime \prime}$, One brain is illustrated at increasing magnification to show the separation between the duplicate barrel subfields. Wp1 is the native field, and Wp2 is the ectopic field. Double arrowheads in $C^{\prime}$ and $C^{\prime \prime}$ indicate dense axonal arbors in the sp/Vlb underlying the duplicate fields $\left(\boldsymbol{C}^{\prime}\right)$ in contrast with little arborization in a control brain $\left(\boldsymbol{C}^{\prime \prime}\right)$. $\mathbf{D}-\mathbf{G}$, In a second brain with fewer labeled axons, individual VB axons can be discerned branching in the sp/VIb $(\boldsymbol{E}-\boldsymbol{G}) . \boldsymbol{F}, \mathbf{G}$, White arrows indicate points of bifurcation; yellow arrows indicate branches heading in the direction of each field. $\boldsymbol{H}, \boldsymbol{I}$, Dense, labeled VB axons in a brain with duplicate subfields; confocal view. $\boldsymbol{J}-\boldsymbol{L}$ are higher-magnification views of boxed areas in $\boldsymbol{H}$ and $\boldsymbol{I}$. Axons form a meshwork in sp/VIb, aligned toward different barrel duplicates ( $\boldsymbol{H}$, white arrows), crossing one another (yellow arrow), and branching toward different duplicates ( $\boldsymbol{J}$ $\boldsymbol{K}$, white, yellow arrows). $\boldsymbol{I}, \boldsymbol{L}$, Duplicate barrels in close proximity; axons cross and branch between duplicates in layer IV. Scale bar (in $\boldsymbol{A}): A, 0.6 \mathrm{~mm} ; \boldsymbol{B}, 0.25 \mathrm{~mm} ; \boldsymbol{C}, 0.2 \mathrm{~mm} ; \boldsymbol{D}, \boldsymbol{E}, 0.1 \mathrm{~mm} ; \boldsymbol{F}, \boldsymbol{G}, \boldsymbol{L}, 30 \mu \mathrm{m} ; \boldsymbol{H}, 60 \mu \mathrm{m} ; \boldsymbol{I}, 90 \mu \mathrm{m} ; \boldsymbol{J}, \boldsymbol{K}, 20 \mu \mathrm{m}$.

the posterior rows somewhat less; therefore, the $\mathrm{C}$ row represents "moderate" shape change. In six flattened cortices, we obtained the ratio of length to width for barrels C1 to C6 (axes used for measurement illustrated in Fig. $1 D, L)$. When the aspect ratios of specific barrels were directly compared between groups, 83\% were larger in experimental animals than in controls. Statistical analysis further indicated a significant difference between the experimental group and controls ( $t$ test, two-sample, $p \leq$ $0.0003)$.

These observations help to characterize the positional information that FGF8/17 confers. FGF8/17 manipulations not only shift or duplicate areas. Our findings suggest an A/P gradient of positional values across the cortical sheet that can be skewed, stretched, or compressed.

\section{Duplicate innervation of duplicate barrels}

The presumption of thalamic innervation based on histochemistry was confirmed by direct axonal tracing. Most striking, dupli-

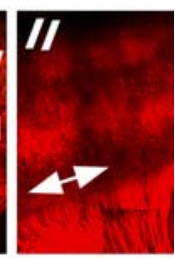

cate barrel fields reflected a transformation of the innervation of the posterior cortex. Small crystals of DiI were deposited into the VB at P5-P6. After diffusion of the tracer from the $\mathrm{VB}$, duplicated fields were visible by DiI fluorescence in whole-brain specimens $(n=3)$. These brains were selected for sectioning in the sagittal plane, together with control brains with single barrel fields. Labeled axon trajectories examined in these P5-P6 brains revealed the result of growth cone decisions made some days previously as axons entered the cortical plate. Thus, the dynamic quality of decision-making was not captured, but final choices were.

The distribution of DiI-labeled axons between duplicate barrel fields suggested an intracortical sorting of VB axons into two separate bundles. After exiting the internal capsule (IC), labeled VB axons separated in the region of layer VIb, the former subplate (Allendoerfer and Shatz, 1994), to form two distinct fields of axonal arbors (Fig. 2A-C'). Within the former subplate, labeled axons crisscrossed beneath the duplicate fields (Fig. $2 H$ ) and bifurcated, with branches directed toward each of the two fields. Such bifurcations were particularly clear in a brain with sparse DiI labeling (Fig. 2D-G) or in brains viewed by confocal microscopy (Fig. $2 \mathrm{H}-\mathrm{K}$ ). This rich meshwork of crossing and branching axons in layer VIb was notably absent in control brains. In P5-P6 controls, layer VIb contained sparsely arborizing axons in transit to upper layers (Fig. 2 $C^{\prime \prime}$ ) (see Fig. 5B). Finally, in a brain in which duplicate fields formed close to one another, additional bifurcating axons were seen in layer IV (Fig. $2 I, L$ ).

No overt changes could be identified in the VB of these mice or when duplicate barrels were identified by histochemistry (Fig. 1) ( $n=8$ P5-P6 mice). In particular, we found no duplication of thalamic barreloids. The results therefore suggest that duplicate cortical barrels in $\mathrm{S} 1$ receive innervation from a common source of VB neurons, whose axons bifurcate within the cortical primordium. Duplication of barrel innervation appears highly likely to be attributable to a duplication of intracortical guidance cues.

Shifting regional identity in the subplate and cortical plate These findings beg the question of which intracortical cell populations carry positional information and provide guidance. A serendipitous discovery was that FGF8 manipulations at different embryonic ages shift molecular regional identity in the subplate and cortical plate either in or out of register. This new tool was used to reveal separate guidance functions in the subplate and cortical plate.

Subplate cells are among the earliest born cortical neurons in several species (Luskin and Shatz, 1985; Kostovic and Rakic, 1990; Allendoerfer and Shatz, 1994). In the present study, bro- 
modeoxyuridine (BrdU) labeling indicated a conspicuous lag between E10.5 and E11.5, separating the onset of generation of the subplate and the cortical plate (Fig. 3A). Electroporation of Cre into $\mathrm{R} 26 \mathrm{R}$ reporter mice suggested that this lag might be critical, allowing electroporation at E10.5, but not E11.5, to affect subplate cells.

Although electroporation-mediated transfection is itself transient, the daughters of transfected progenitors can be labeled permanently in R26R mice. As in other electroporation experiments, biological effects on the embryo do not begin until a few hours after the procedure, when the protein product of the transfected gene is expressed (Yasuda et al., 2000; Tabata and Nakajima, 2001). In R26R mice, the production of Cre recombinase protein and Cre-mediated recombination at loxP sites activate expression of $\beta$-gal, thereby labeling transfected cells and their progeny. The distribution of $\beta$-gal-positive cells in R26R cortex therefore provides insight into which cortical cell layers can be influenced by electroporation at a given embryonic age.

After Cre electroporation at either E10.5 or E11.5, $\beta$-galpositive cells were seen at P6 throughout layers II-VIa (Fig. $3 B, E)$. Importantly, this observation suggests that Fgf8 electroporation at E11.5 is early enough for excess FGF8 to influence the progenitors of cells in deep neocortical layers. Supporting this conclusion, Fgf8 electroporation at E11.5 caused equivalent shifts of gene expression in deep, mid, and upper layers of the neocortex (Fig. 4, and data not shown).

In contrast, $\beta$-gal-positive cells outlined the subplate in mice electroporated with Cre at E10.5 but were sparse after electroporation at E11.5 (Fig. 3C, D, F, G). Consistent with this, Fgf8 electroporation at E10.5 or E11.5 had markedly different effects on regional gene expression in the subplate. Electroporation at E10.5 generated a posterior shift in expression of ephrinA5 or p75 in both the subplate and the cortical plate (Fig. $3 H-K$ ). After Fgf8 electroporation at E11.5 or E12.5, however, ephrin and p75 expression shifted posteriorly in the cortical plate but not the subplate (Fig. 3L-N) (supplemental Fig. 2, available at www.jneurosci.org as supplemental material).

\section{A shift in the cortical plate alone reveals area-specific guidance by layer IV}

We next tested the effects of shifting regional identity in or out of register in the subplate and cortical plate. In control brains examined at P5-P6, DiI-labeled VB axons left the IC and crossed the subplate/VIb to form axonal arbors in VIa and in the barrel hollows of layer IV. Arborization in layers IV and VIa was aligned along the A/P axis (Fig. 5A-C). As anticipated, after Fgf8 electroporation at E11.5, the anterior boundary of S1, histologically identifiable at P5-P6, shifted posteriorly; furthermore, labeled VB axon arbors filled individual barrels in layer IV of shifted S1 (Fig. 5E,G), confirming and extending previous findings (Fukuchi-Shimogori and Grove, 2001).

Other findings were more surprising. The overall laminar pattern of VB innervation of S1was not simply shifted, but skewed. VB axons invaded from the IC anterior to the histological boundary of $\mathrm{S} 1$ (Fig. $5 F$ ). A dense plexus of labeled VB axons formed ectopically immediately above the entry point in layer VIa and VIb. Like the meshwork of layer VIb axons that appears in brains with duplicate barrels, this dense arborization in layer V1b is not seen in S1 of control mice. VB axons then tracked posteriorly to enter shifted S1 and innervate layer IV (Fig. 5F,G). A similar misaligned laminar pattern of innervation appeared in brains analyzed at P1 (Fig. 5D,H). Regional shifts in these P1 brains
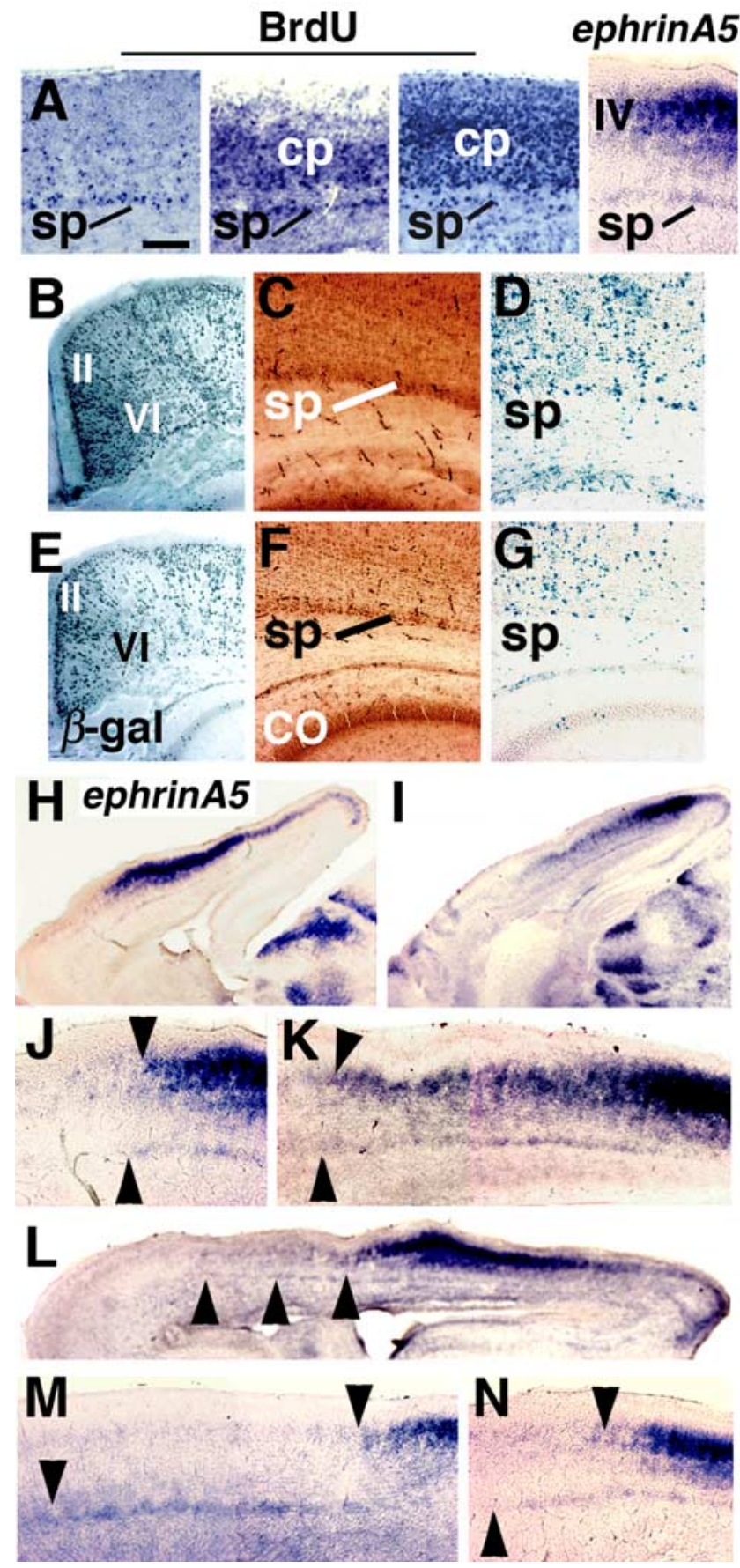

Figure 3. Regional identity in the subplate and cortical plate can be shifted in or out of register. $A$, Early formation of the subplate (sp) versus the cortical plate (cp) detected by BrdU immunohistochemistry at P1, after single BrdU injections at E10.5, E11.5, and E12.5 (left to right). Newborn subplate cells appear at E10.5 and peak in number at E11.5. AtE11.5 and E12.5, both subplate and cortical plate postmitotic cells are detected. In situ hybridization reveals ephrinA5 expression in both the cortical plate and subplate ( $\boldsymbol{A}$, far right). $\boldsymbol{B}-\mathbf{G}$, Coronal sections, medial to left. After Cre electroporation into R26R embryos at either E10.5 or E11.5, $\beta$-galpositive daughter cells are seen at $\mathrm{P} 6$ throughout layers II-Vla. sp/VIb is outlined by blue cells after Cre electroporation at E10.5; fewer labeled subplate cells appear after electroporation at E11.5 (B-G). $\boldsymbol{H}-\boldsymbol{N}$, Sagittal sections of P1 brains, anterior to left. $\boldsymbol{H}, \boldsymbol{I}$, Expression of ephrinA5, marked in developing $\mathrm{S1}(\boldsymbol{H})$, is shifted posteriorly after Fgf8 electroporation at E10.5 (I).J, $\boldsymbol{K}$, EphrinA5 expression is in register along the A/P axis in the subplate and developing layer IV (arrowheads) in control cortex $(J)$ and remains in register after Fgf8 electroporation at E10.5, with a posterior shift in both layers $(\boldsymbol{K})$. Electroporation of $F g f 8$ at E11.5 $(\boldsymbol{M})$ or E12.5 $(\boldsymbol{L}, \boldsymbol{N})$ shifts layer IV but not subplate expression $(L-N)(n=11)$. Arrowheads indicate displaced subplate expression in $\boldsymbol{L}$ and the gap between expression in subplate and layer IV in $\boldsymbol{M}$ and $\boldsymbol{N}$. Scale bar (in $\boldsymbol{A}): A, C, \boldsymbol{D}, \boldsymbol{F}, \boldsymbol{G}, \boldsymbol{J}, \boldsymbol{K}, \boldsymbol{M}, \boldsymbol{N}, 0.2 \mathrm{~mm} ; \boldsymbol{B}, \boldsymbol{E}, 0.3 \mathrm{~mm} ; \boldsymbol{H}, \boldsymbol{I}, 0.5 \mathrm{~mm} ; \boldsymbol{L}, 0.4$. 


\section{Tbr1 mid-layers COUP-TF1 layer 6}
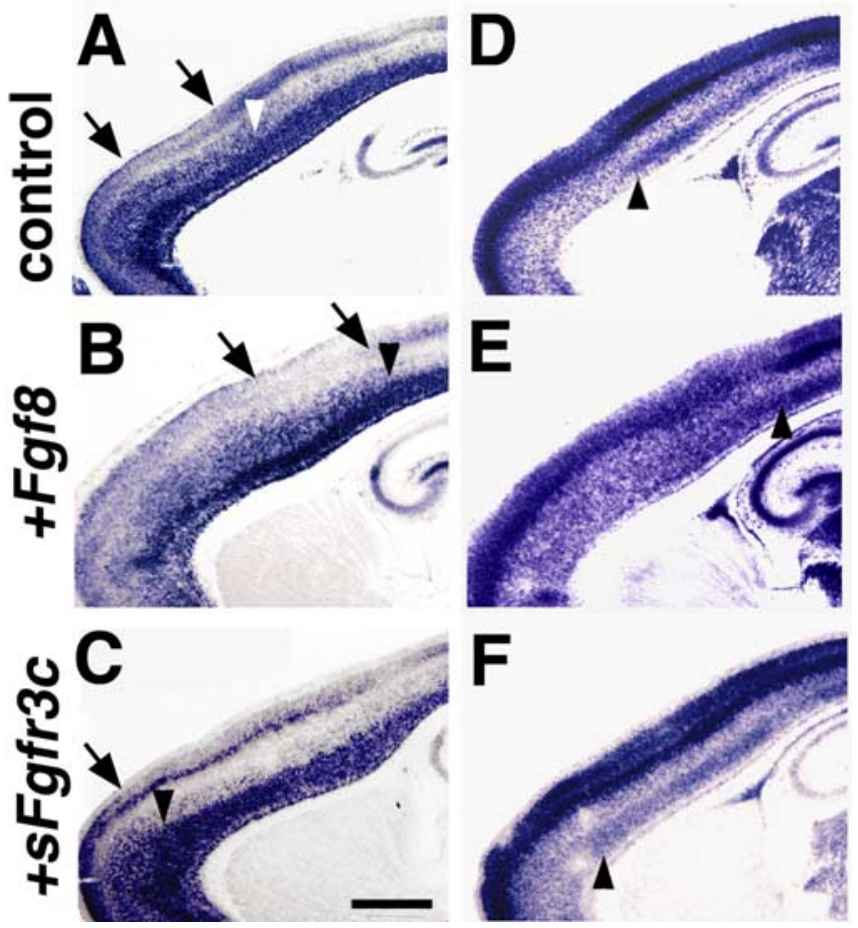

Figure 4. FGF manipulations at E11.5 influence regional identity in deep neocortical layers. $\boldsymbol{A}-\boldsymbol{F}$, Sagittal sections through electroporated and control brains harvested at $\mathrm{P} 6$ and processed with in situ hybridization to reveal regional and laminar transitions in Tbr1 and COUP-TF1 gene expression. A transition in Tbr1 expression appears in the midlayers of anterior cortex ( $\boldsymbol{A}$, arrowhead); this coincides approximately with a transition in COUP-TF1 expression in layer Vla ( $\boldsymbol{D}$, arrowhead). The transition in expression of both genes is shifted posteriorly by excess anterior FGF8 (arrowheads, $\boldsymbol{B}, \boldsymbol{E}$ ) and anteriorly by reduced FGF8/17 activity (arrowheads, $\boldsymbol{C}, \boldsymbol{F}$ ). Notably, the extent of the shift appears equivalent in both midlayer Tbr 1 expression and layer Vla COUPTF1 expression $(\boldsymbol{B}, \boldsymbol{E}$ and $\boldsymbol{C}, \boldsymbol{F})$. Regional transitions in expression also shift in upper layers. For example, a region of low $\mathrm{Tbr} 1$ expression (arrows in $\boldsymbol{A}$ ) is shifted posteriorly by excess FGF8 (arrows in $\boldsymbol{B}$ ). In a brain with reduced FGF8/17, anterior and posterior regions of high $\mathrm{Tbr} 1$ expression appear to merge (arrow in $\boldsymbol{C}$ ). Scale bar (in $\boldsymbol{C}): \boldsymbol{A}-\boldsymbol{F}, 1.0 \mathrm{~mm}$.

were confirmed by posterior shifts in the expression of ephrin-A5, expressed in perinatal $\mathrm{S} 1$, and COUP-TF1.

Skewed innervation represented a route correction by VB axons and indicated redirection by area-specific cues within the developing cortex. Furthermore, these cues appeared specifically associated with the cells of developing layer IV. Redirection to shifted layer IV was consistent across all brains assessed after anterior Fgf8 electroporation at E11.5 $(n=6)$ and indicates that area-specific guidance cues in the cortical plate can also be associated with the cells of particular emerging neocortical layers.

Shifts in cortical plate and subplate produce a coordinated shift in $\mathrm{S} 1$ innervation

Why were VB axons able to redirect fully to layer IV of shifted S1, but not to layer VI, given that regional identity appears to shift (Fig. 4) in both neocortical layers after Fgf8 electroporation at E11.5? One possibility is that regional cues in the subplate are required for a normal laminar pattern of innervation in the cortex.

The distorted innervation pattern is interpretable if Fgf electroporation at E11.5 caused a mismatch in positional values between the subplate and cortical plate. VB axons crossed the subplate anterior to $\mathrm{S} 1$ and arborized immediately because guidance cues associated with the subplate had not shifted. Indeed, axons
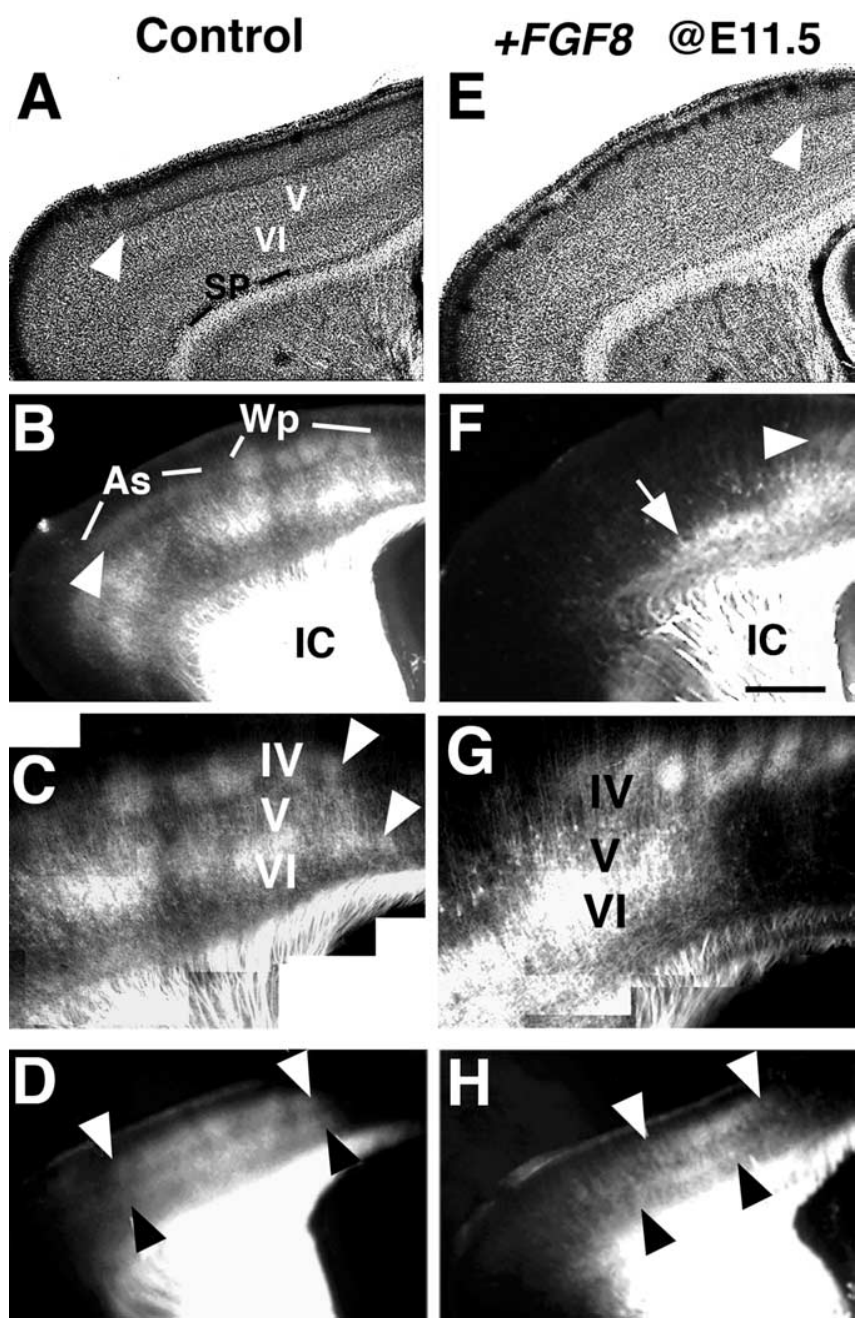

Figure 5. A regional shift in the cortical plate alone leads to skewed innervation of $S 1 . \boldsymbol{A}-\boldsymbol{H}$, Sagittal sections through two control brains $(\boldsymbol{A}-\boldsymbol{D})$ and two brains electroporated with Fgf8 anteriorly at E11.5 $(\boldsymbol{E}-\boldsymbol{H})$. Anterior is to the left. Brains were harvested at P5 $(\boldsymbol{A}-\boldsymbol{C}, \boldsymbol{E}-\boldsymbol{G})$ or P1 $(\boldsymbol{D}, \boldsymbol{H}) . \boldsymbol{A}, \boldsymbol{E}$, Nissl-stained sections show the transition (arrowheads) at $\mathrm{P} 5$ between $\mathrm{S} 1$ and motor cortex. Layers IV and V are distinct in S1 but not in motor cortex, anterior to S1. As expected, the anterior boundary of $\mathrm{S} 1$ is shifted posteriorly in the Fgf8-electroporated brain (compare arrowheads in $\boldsymbol{A}, \boldsymbol{E}$ ). $\boldsymbol{B}, \boldsymbol{C}$, In the control P5 brain, Dil-labeled VB axons enter S1 ( $\boldsymbol{B}$, arrowhead marks anterior $S 1$ boundary) and form axonal arbors that lie in register in layers Vla and IV (arrowheads, $\mathbf{C}$. F, G, After electroporation of Fgf8 at E11.5, VB axons enter the cortex (arrow in $\boldsymbol{F}$ ) anterior to the $S 1$ boundary (arrowheads in $\boldsymbol{E}, \boldsymbol{F}$ ) and travel posteriorly through layers $\mathrm{V}$ and $\mathrm{VI}$ before correctly forming barrel arbors in layer IV of shifted $\mathrm{S} 1(\boldsymbol{G})$. Consequently, axonal arbors in layers VI and IV are out of register (compare $\mathbf{C}, \boldsymbol{G}) . \boldsymbol{D}, \boldsymbol{H}$, A similar contrast in VB axon trajectory is seen at $P 1$ between control and electroporated brains. Scale bar (in $\boldsymbol{E}): \boldsymbol{A}, \boldsymbol{B}, \boldsymbol{D}$, $\boldsymbol{E}, \boldsymbol{F}, \boldsymbol{H}, 0.5 \mathrm{~mm} ; \boldsymbol{C}, \boldsymbol{G}, 0.3 \mathrm{~mm}$. SP, Subplate; As, anterior snout subfield.

traversed a region of the subplate that presumably retained its "S1" identity. To test this interpretation, $F g f 8$ was electroporated at E10.5. In this case, regional identity is predicted to shift, in register, in both subplate and cortical plate. Thalamic axons should successfully seek out their target area in the subplate, resulting in a wholesale shift of S1 innervation.

The results supported both this prediction and the general hypothesis that the subplate and cortical plate contain distinct guidance cues that can be teased apart but normally act in concert. In all brains analyzed at P5 after electroporation at E10.5, VB axons emerged from the IC in approximately the same position as in control brains and brains electroporated at E11.5 (Fig. 6, compare $A, C$ ) but then curved sharply (Fig. $6 A$, white arrow, $B$, 

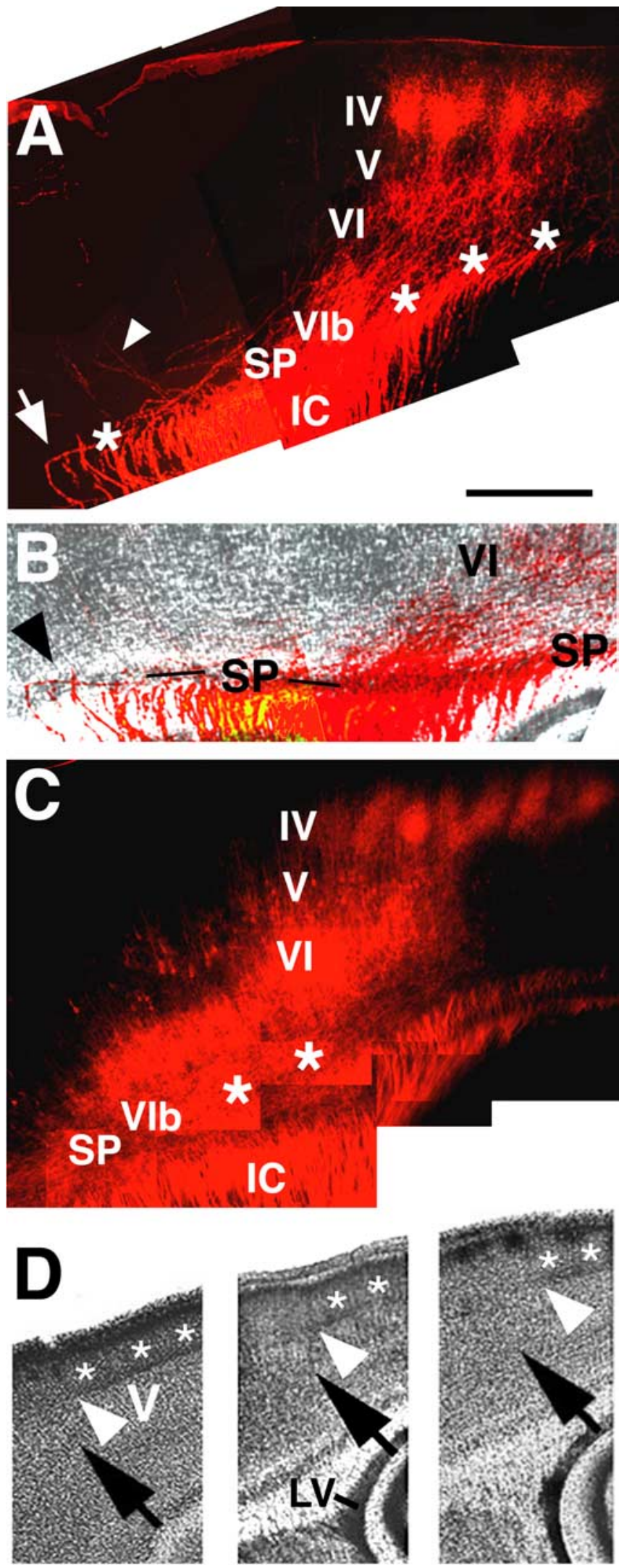

Figure 6. Regional shifts in both the subplate and cortical plate gives a wholesale shift in innervation of S1. A-D, Sagittal sections, P5 brains. A, P5 brain electroporated at E10.5 [subplate (sp) and cortical plate presumed shifted in register]. $\boldsymbol{B}$, Image of Dil-labeled axons in $\boldsymbol{A}$ superimposed onto a Nissl-stained section from the same brain. C, P5 brain electroporated at E11.5 (subplate and cortical plate presumed out of register; higher magnification of Fig. 5G). D, Sections stained for Nissl to indicate the anterior boundary of S1 (black arrows). From left to arrowhead) to run posteriorly in the subplate/VIb (Fig. $6 B$ ), toward the new anterior boundary of S1. VB axons then exited the subplate into shifted $\mathrm{S} 1$ to form aligned axonal arbors in layers IV and VIa $(n=5)$ (Fig. $6 A)$, resembling the alignment seen in control brains (Fig. $5 B, C$ ). Notably, the aligned pattern in layers IV and VI was also seen in duplicated barrel fields after posterior Fgf8 electroporation at E10.5, early enough to alter regional identity in the subplate. In the latter brains, the subplate/VIb was marked by profuse axon branching in the direction of each duplicate field.

\section{Reproducibility of altered thalamocortical trajectories}

As noted in Materials and Methods, Fgf8-electroporated and control hemispheres were selected for additional analysis based on DiI labeling of the distinctive S1 barrels, visible in intact brains. The ratio between total and selected brains therefore reflects the practical success of several sequential experimental steps, not the reproducibility of FGF8-induced effects on thalamocortical innervation. Several other considerations, however, indicate that the effects are highly reproducible.

First, we observed a one-to-one correlation, in both control and experimental groups, between the site of DiI-labeled VB innervation and the position of S1 barrel fields indicated by Nissl staining. This suggests that the sampling procedure did not exclude brains with shifted S1 but no shift in innervation or brains with VB axons misdirected to the wrong area. Rather, the process consistently selected brains with shifts or duplications in morphologically identifiable S1 barrel fields.

Second, selection was not based on detailed features of thalamocortical innervation, which were not visible until the brains were sectioned. Thus, in the absence of an obvious selection bias, we saw distinctive VB thalamocortical axon trajectories that were qualitatively consistent, in detail, within an experimental group. Brains electroporated with $F g f 8$ at E10.5 showed a fully shifted VB innervation of S1 $(n=5)$, whereas those electroporated at E11.5 showed a skewed pattern $(n=6)$. In the latter, axons crossed the subplate anterior to S1, formed abnormal arbors in layer VIb, and then traveled posteriorly to innervate the barrels of shifted layer IV. In brains with duplicate barrels $(n=3)$, $\mathrm{VB}$ axons divided in the subplate/layer VIb, forming a network of crossing and dividing axons that is not seen in control P5 brains.

Third, shifts in VB innervation of layer IV barrels were consistent in size across brains electroporated with $F g f 8$ at either E10.5 or E11.5 and analyzed at P5. In six P5 brains, DiI labeled the most anterior large barrels of the Wp subfield. We measured shifts in the A/P position of these barrels in sagittal sections, matched for mediolateral position in the hemisphere. The most anterior Wp barrel in Fgf8-electroporated brains was shifted pos-

$\leftarrow$

right, Control brain also shown in Figure 5A; brain electroporated at E10.5 shown in top panels; brain electroporated at E11.5 also shown in Figure $5 E$. In the latter two brains, the $\$ 1$ boundary is shifted posteriorly, to approximately the same extent, to a point above the lateral ventricle (LV). White arrowheads and asterisks indicate anterior barrels. After electroporation at either E10.5 or E11.5, VB axons arrive beneath the cortical primordium anterior to the shifted S1 boundary, but the pattern of VB innervation is skewed only in $\boldsymbol{C}$, not $\boldsymbol{A}$. VB axons in the E10.5 electroporated brain curve toward the correct target area just beneath the subplate (arrow in $\boldsymbol{A}$ ) and complete their route correction primarily within sp/Vlb (asterisks). A white arrowhead in $\boldsymbol{A}$ indicates one of the few stray axons entering the wrong part of the cortex. $\ln B, \mathrm{sp} / \mathrm{Vlb}$ is a dense line of cells; labeled axons change course close to or within this layer. Axons enter the cortex proper near the anterior S1 border to form arbors in layers IV and Vla. In sharp contrast with the brain electroporated only $1 \mathrm{~d}$ later $(\boldsymbol{C})$, arbors in layers IV and Vla are aligned $(\boldsymbol{A})$ as in control brains. Scale bar (in $\boldsymbol{A}$ ): $\boldsymbol{A}-\boldsymbol{C}, 0.5 \mathrm{~mm} ; \boldsymbol{D}, 0.6 \mathrm{~mm}$. 


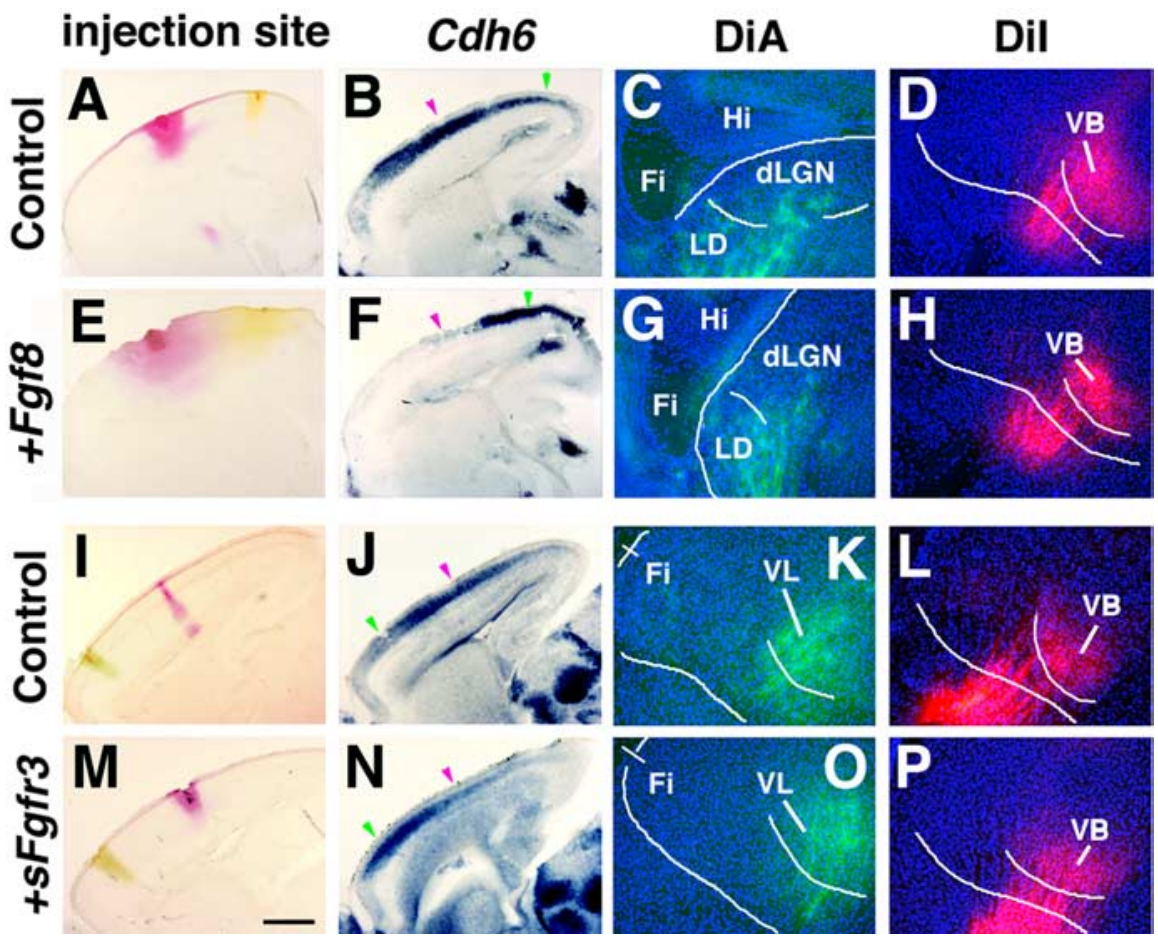

Figure 7. Thalamocortical projections labeled just before birth appear unchanged by intracortical FGF8 manipulations. $\boldsymbol{A}-\boldsymbol{P}$, Sagittal sections, E17.5 brains, anterior to the left. Each row of panels illustrates sections from a single brain. Brains electroporated anteriorly with Fgf8 or SFgfr3 $\mathrm{C}$ were matched with controls, and Dil and DiA crystals were placed in comparable cortical locations in matched pairs $(\boldsymbol{A}-\boldsymbol{D} / \boldsymbol{E}-\boldsymbol{H}$ and $\boldsymbol{I}-\boldsymbol{L} / \boldsymbol{M}-\boldsymbol{P})$. Dil crystals (red) were positioned in parietal and DiA (yellow) in occipital $(\boldsymbol{A}, \boldsymbol{E})$ or frontal $(\boldsymbol{I}, \boldsymbol{M})$ domains. Assessed by regional expression of $(\mathrm{dh} 6(\boldsymbol{B}, \boldsymbol{F}, \boldsymbol{J}, \boldsymbol{N})$, cortical domains were shifted posteriorly by Fgf8 electroporation and anteriorly by sFgfr3c. Consequently, in each matched pair, dye deposits were placed in the same relative positions but in different cortical domains (compare $\boldsymbol{A}, \boldsymbol{B}$ with $\boldsymbol{E}, \boldsymbol{F}$ and $\boldsymbol{I}, \boldsymbol{J}$ with $\boldsymbol{M}, \boldsymbol{N}$ ). Dil and DiA labeling in the thalamus reflected only the position of the dye deposit, not shifts in domain identity. DiA and Dil labeled the dorsal lateral geniculate nucleus (dLGN), lateral dorsal (LD), and ventrobasal $(\mathrm{VB})$ nuclei $(\boldsymbol{C}, \boldsymbol{D}, \mathbf{G}, \boldsymbol{H})$ or VB and ventrolateral $(\mathrm{VL})(\boldsymbol{K}, \boldsymbol{L}, \mathbf{O}, \boldsymbol{P})$ in both control and shifted $(n=$ 16) brains (white lines indicate outline of the thalamus and relevant nuclei). Sections counterstained with Hoechst. Scale bar (in $\boldsymbol{M}): \boldsymbol{A}, \boldsymbol{B}, \boldsymbol{E}, \boldsymbol{F}, \boldsymbol{I}, \boldsymbol{J}, \boldsymbol{M}, \boldsymbol{N}, 0.65 \mathrm{~mm} ; \boldsymbol{C}, \boldsymbol{D}, \boldsymbol{G}, \boldsymbol{H}, \boldsymbol{K}, \boldsymbol{L}, \mathbf{0}, \boldsymbol{P}, 0.2 \mathrm{~mm}$. Fi, Fimbria; Hi, hippocampus.

teriorly compared with controls, by a mean of $1.1 \pm 0.1 \mathrm{~mm}$. For scale, the mouse cortical hemisphere at P5 is $\sim 7 \mathrm{~mm}$ in length. The A/P position of the most anterior $\mathrm{Wp}$ barrel differed significantly between control and $F g f 8$-electroporated brains (paired $t$ test, $\mathrm{p} \leq 0.0001$ ).

Independence of intracortical and subcortical guidance cues Previous studies indicate that, as axons exit the thalamus and traverse the IC toward the cortex, they are directed and sorted by subcortical guidance mechanisms (Braisted et al., 2000; Garel et al., 2002; Hevner et al., 2002; Lopez-Bendito et al., 2002; Dufour et al., 2003; Seibt et al., 2003; Garel and Rubenstein, 2004). In this way, thalamic axons are appropriately distributed beneath the cortical mantle by guidance cues outside the developing cortex. After leaving the IC, however, thalamocortical axons have farther to travel before they reach their target areas, requiring continued guidance. Present and previous findings indicate a degree of independence, at least initially, between the subcortical and intracortical mechanisms that guide thalamocortical axons.

In neonatal mice that are FGF8 hypomorphs, the cortical area map is rearranged with respect to area and regional gene expression patterns (Garel et al., 2003), as well as intracortical connections (Huffman et al., 2004), but not with respect to the pattern of thalamocortical projections, labeled from the cortex (Garel et al., 2003). An electroporation experiment at E11.5, in which we labeled thalamocortical axons at E17.5, produced similar results
(Fig. $7 A-P$ ). As in the previous study (Garel et al., 2003), DiI and DiA crystals were deposited in the same relative positions in control cortex, and cortices in which presumptive areas were shifted. In both sets of brains, the same thalamic nuclei and axon trajectories were labeled, although in brains with shifted area maps, this pattern of thalamic label was now inappropriate.

At E17.5 in the mouse, most thalamic axons are still growing toward the cortex; only a few have entered the deep cortical plate, whereas others "wait" in the subplate (Molnar et al., 2002). Based on our findings, we expect electroporation at E11.5 to be too late to change the regional identity of the subplate. Thus, if axons have not been resorted subcortically, they will arrive and wait in an unshifted, inappropriate position, leading to the observed pattern of thalamic labeling. A second explanation for our results is that DiI and DiA deposits primarily labeled the extracortical section of the thalamocortical pathway. Together with previous findings axons (Garel et al., 2003), these observations strongly suggest that FGF8-regulated positional cues in the cortical primordium neither require nor immediately elicit changes in the initial subcortical trajectory of thalamocortical axons.

\section{Discussion}

Previous findings appeared to pit against one another the importance of factors intrinsic to the cortical primordium in setting up the neocortical area map (Rakic, 1988; Rubenstein et al., 1999; O’Leary and Nakagawa, 2002; Grove and Fukuchi-Shimogori, 2003) versus the control of thalamocortical innervation, a signal feature of area identity, by subcortical mechanisms (Lopez-Bendito and Molnar, 2003; Garel and Rubenstein, 2004). A more comprehensive view is that several positional guidance cues direct thalamic axons to specific areas. Initially, thalamocortical axons are sorted in the IC by subcortical molecular guidance cues that are themselves independent of the cortex (Braisted et al., 2000; Garel et al., 2002; Hevner et al., 2002; Lopez-Bendito et al., 2002; Dufour et al., 2003; Seibt et al., 2003; Garel and Rubenstein, 2004) and from intracortical FGF8/17 signaling (present study). Once axons reach the subplate, they are guided sequentially by positional information in the subplate and the developing layers of the cortical plate (Ghosh et al., 1990, 1993; present study). Intracortical and subcortical mechanisms can function together to guide thalamocortical innervation because they are normally in spatial register. The multiplicity of guidance steps is disclosed, as in the present study, when the cues are pulled out of register (Fig. 8).

A surprising observation was that cortical plate cues not only directed axons to area S1 but also, more specifically, to layer IV of S1. This may be an example of a general association between area-specific guidance and particular cortical layers, a phenomenon that does not appear to have been described previously. Strong previous evidence for area-specific, thalamic axon guid- 

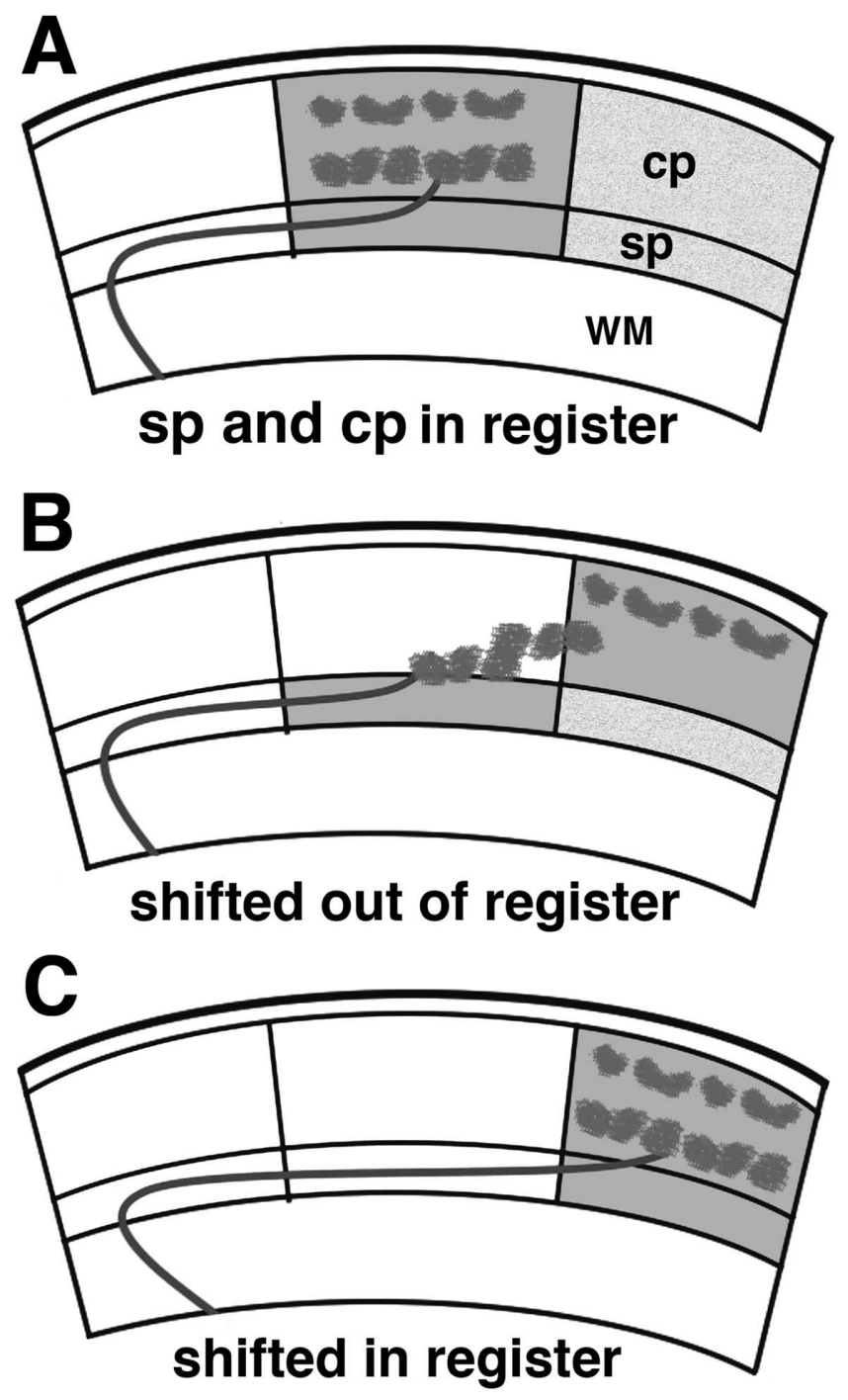

Figure 8. Regional identities in the subplate (sp) and cortical plate (cp) define axon trajectories. $A-C, A$ region of neocortex in sagittal section; posterior is to the right. Presumptive $S 1$ is dark gray, an area posterior to $S 1$ is light gray, and other areas are white. A dark gray line represents the VB axon trajectory. $A$, In a nonelectroporated brain, VB axons exit the white matter (WM) and travel through the subplate to the dark gray region, in which they enter the cortical plate and form aligned axon arbors in layers IV and Vla. $\boldsymbol{B}$, Only the cortical plate is shifted posteriorly. VB axons enter the cortex through dark gray subplate, form ectopic arbors in the white cortical plate immediately above, and finally grow posteriorly toward dark gray cortical plate. Once there, axons form appropriate arbors in layer IV, but not Vla. In C, both the cortical plate and the subplate have shifted in register. VB axons find the posteriorly shifted dark gray region of the subplate, enter the cortical plate, and form normally aligned axon arbors.

ance cues in the cortical primordium came from studies in rat in which explants of the embryonic cortical primordium were grafted ectopically into a newborn host cortex (Barbe and Levitt, 1992, 1995; Frappe et al., 1999, 2001; Gaillard and Roger, 2000). These explants exerted a robust attraction for input from the host thalamus, but axon termination within the explant was diffuse, giving no clues to the cellular basis of the attraction.

The suggestion that individual cortical layers provide areaspecific guidance to thalamic axons fits well with a classic, primary definition of an area. In traditional cortical maps, areas were distinguished by differences in layer morphology, one of the clearest transitions being that from the agranular layer IV of primary motor cortex to granular layer IV of primary somatosensory cortex (Brodmann, 1909; Nauta and Feirtag, 1986). That is, individual neocortical layers have area boundaries themselves, with layer IV as a marked example. In this context, layer-derived, area-specific guidance cues are not surprising. Particularly given the present findings, these cues deserve additional study.

An unexpected finding was that the laminar pattern of thalamic innervation in an area depends on a match between positional cues in the subplate and cortical plate. When regional identity was shifted in the cortical plate alone, the normally aligned layer pattern of input to S1 was skewed. VB axons innervated the barrels in layer IV of shifted S1 but not layer VI. Instead, arbors formed in deep layers well outside the boundaries of S1. This finding appeared to defy evidence that regional identity in layers IV and VI themselves had been shifted equivalently. Only when regional identity in the subplate was shifted as well did the normal, aligned laminar pattern of VB innervation reemerge in S1. These observations suggest that the subplate regulates the laminar pattern of thalamic innervation. The subplate might, for example, prepare VB axons to respond to deep layer guidance cues. Alternatively, VB axons may arborize in deep layers as a default, once the axons cross what they read as the "correct" area of subplate.

Previous findings show that thalamic axons must interact with subplate cells to recognize target areas (Ghosh et al., 1990; Ghosh and Shatz, 1993; Allendoerfer and Shatz, 1994; O'Leary et al., 1994; Molnar et al., 1998b). When the subplate beneath primary sensory cortex was ablated in the cat, axons from sensory thalamus did not enter the cortical plate, either in the target area or in other areas with an intact subplate (Ghosh et al., 1990; Ghosh and Shatz, 1993). In the present study, regional identity in the subplate was shifted, and thalamic axons altered their trajectory to match this shift. Current findings therefore complement previous observations and support the general hypothesis that the subplate is needed for spatial guidance of thalamic axons in a variety of species.

Thalamic axons interact with subplate cells via functional synapses (Friauf et al., 1990; Ghosh and Shatz, 1993; Allendoerfer and Shatz, 1994), leading to the proposal that activity-based competition among axons could prune collaterals and determine the site of entry for thalamic axons (Friauf et al., 1990; Ghosh and Shatz, 1993; Allendoerfer and Shatz, 1994) (but see Molnar et al., 2002). In this way, position across the cortical sheet could be determined by an interaction between thalamic axons and subplate cells. We suggest that the subplate already contains positional cues that provide thalamic axon guidance.

Previous and present findings further combine to indicate the primacy of subplate cues over those in the cortical plate. Lacking a subplate, presumptive visual cortex fails to attract axons from the lateral geniculate nucleus, despite normal target neurons in developing layer IV (Ghosh et al., 1990; Ghosh and Shatz, 1993). Thalamic axons are also indifferent to potential cortical plate cues in the reeler mutant mouse, until the axons reach an ectopic subplate, or superplate, near the pial surface of the cortex (Molnar et al., 1998a). Our observations, too, suggest that layer IV cells are associated with strong, area-specific attractant cues but that thalamic axons are unresponsive before crossing the subplate.

Overall, our findings implicate FGF8/17 signaling in initiating developmental events that, in turn, position axon guidance signaling molecules and growth factors in the cortical primordium (Fukuchi-Shimogori and Grove, 2001; 2003; and present study). FGF8/17 signaling has been shown to regulate gene expression of appropriate adhesion and guidance molecules, such as cadherins and ephrin/Ephs (Fukuchi-Shimogori and Grove, 2001, 2003; Garel et al., 2003) (our unpublished data), that are regionally 
distributed (Suzuki et al., 1997; Inoue et al., 1998; Mackarehtschian et al., 1999; Miyashita-Lin et al., 1999; Nakagawa et al., 1999; Yun et al., 2003) and associated with thalamocortical axon growth and guidance (Gao et al., 1998; Takemoto et al., 2002). Ephrin-A5 is one example of a likely mediator of FGF8/17 signaling. Altering FGF8/17 levels shifts the neocortical ephrin-A5 expression gradient (Fig. 4C, and data not shown). Mice lacking ephrin-A5 show abnormalities in the targeting of thalamic axons to somatosensory cortex (Uziel et al., 2002), as well as differences in the size and shape of S1 barrels (Prakash et al., 2000; Vanderhaeghen et al., 2000).

Neurotrophins and their receptors form another category of area-specific regulators of thalamic innervation. No longer commonly associated with directional axon guidance, neurotrophins and their receptors may be present at the right time and place to promote the growth of axons into a target. Thus, both p75 and neurotrophin 3 (NT3) influence thalamic innervation of specific areas (Mackarehtschian et al., 1999; McQuillen et al., 2002). Regional gene expression of both p75 and NT3 supports their regional effects (Lee et al., 2000; Vigers et al., 2000; Ma et al., 2002) and can be regulated by FGF8 (present study; our unpublished data).

In summary, our findings clarify the relationship between subcortical and intracortical guidance of thalamocortical projections and reveal sequential, positional cues in the subplate and cortical plate. Early patterning events, associated with FGF8/17 signaling (Fukuchi-Shimogori and Grove, 2001), lead to the postnatal differentiation of many neocortical area-specific features, including barrel histology and histochemistry, early intraneocortical projections and a defining feature of a cortical areaspecific, patterned innervation from the thalamus (FukuchiShimogori and Grove, 2001; Hamasaki et al., 2004; Huffman et al., 2004; present study). The challenge now is to identify the steps between FGF8/17 regulation of the initial neocortical map and area differentiation.

\section{References}

Allendoerfer KL, Shatz CJ (1994) The subplate, a transient neocortical structure: its role in the development of connections between thalamus and cortex. Annu Rev Neurosci 17:185-218.

Barbe MF, Levitt P (1992) Attraction of specific thalamic input by cerebral grafts depends on the molecular identity of the implant. Proc Natl Acad Sci USA 89:3706-3710.

Barbe MF, Levitt P (1995) Age-dependent specification of the corticocortical connections of cerebral grafts. J Neurosci 15:1819-1834.

Bishop KM, Goudreau G, O'Leary DD (2000) Regulation of area identity in the mammalian neocortex by Emx2 and Pax6. Science 288:344-349.

Bishop KM, Rubenstein JL, O'Leary DD (2002) Distinct actions of Emx1, Emx2, and Pax6 in regulating the specification of areas in the developing neocortex. J Neurosci 22:7627-7638.

Bishop KM, Garel S, Nakagawa Y, Rubenstein JL, O'Leary DD (2003) Emxl and Emx2 cooperate to regulate cortical size, lamination, neuronal differentiation, development of cortical efferents, and thalamocortical pathfinding. J Comp Neurol 457:345-360.

Braisted JE, Catalano SM, Stimac R, Kennedy TE, Tessier-Lavigne M, Shatz CJ, O'Leary DD (2000) Netrin-1 promotes thalamic axon growth and is required for proper development of the thalamocortical projection. J Neurosci 20:5792-5801.

Brodmann K (1909) Vergleichende Lokalisationslehre der Grosshirnrinde in ihren Prinzipien dargestellt auf Grund des Zellenbaues. Leipzig, Germany: J. A. Barth.

Donoghue MJ, Rakic P (1999a) Molecular evidence for the early specification of presumptive functional domains in the embryonic primate cerebral cortex. J Neurosci 19:5967-5979.

Donoghue MJ, Rakic P (1999b) Molecular gradients and compartments in the embryonic primate cerebral cortex. Cereb Cortex 9:586-600.

Dufour A, Seibt J, Passante L, Depaepe V, Ciossek T, Frisen J, Kullander K,
Flanagan JG, Polleux F, Vanderhaeghen P (2003) Area specificity and topography of thalamocortical projections are controlled by ephrin/Eph genes. Neuron 39:453-465.

Erzurumlu RS, Jhaveri S (1990) Thalamic axons confer a blueprint of the sensory periphery onto the developing rat somatosensory cortex. Brain Res Dev Brain Res 56:229-234.

Erzurumlu RS, Jhaveri S, Benowitz LI (1990) Transient patterns of GAP-43 expression during the formation of barrels in the rat somatosensory cortex. J Comp Neurol 292:443-456.

Frappe I, Roger M, Gaillard A (1999) Transplants of fetal frontal cortex grafted into the occipital cortex of newborn rats receive a substantial thalamic input from nuclei normally projecting to the frontal cortex. Neuroscience 89:409-421.

Frappe I, Gaillard A, Roger M (2001) Attraction exerted in vivo by grafts of embryonic neocortex on developing thalamic axons. Exp Neurol 169:264-275.

Friauf E, McConnell SK, Shatz CJ (1990) Functional synaptic circuits in the subplate during fetal and early postnatal development of cat visual cortex. J Neurosci 10:2601-2613.

Fukuchi-Shimogori T, Grove EA (2001) Neocortex patterning by the secreted signaling molecule FGF8. Science 294:1071-1074.

Fukuchi-Shimogori T, Grove EA (2003) Emx2 patterns the neocortex by regulating FGF positional signaling. Nat Neurosci 6:825-831.

Gaillard A, Roger M (2000) Early commitment of embryonic neocortical cells to develop area-specific thalamic connections. Cereb Cortex 10:443-453.

Gao PP, Yue Y, Zhang JH, Cerretti DP, Levitt P, Zhou R (1998) Regulation of thalamic neurite outgrowth by the Eph ligand ephrin-A5: implications in the development of thalamocortical projections. Proc Natl Acad Sci USA 95:5329-5334.

Garel S, Rubenstein JL (2004) Intermediate targets in formation of topographic projections: inputs from the thalamocortical system. Trends Neurosci 27:533-539.

Garel S, Yun K, Grosschedl R, Rubenstein JL (2002) The early topography of thalamocortical projections is shifted in Ebf1 and Dlx1/2 mutant mice. Development 129:5621-5634.

Garel S, Huffman KJ, Rubenstein JLR (2003) Molecular regionalization of the neocortex is disrupted in Fgf8 hypomorphic mutants. Development 130:1903-1914.

Ghosh A, Shatz CJ (1993) A role for subplate neurons in the patterning of connections from thalamus to neocortex. Development 117:1031-1047.

Ghosh A, Antonini A, McConnell SK, Shatz CJ (1990) Requirement for subplate neurons in the formation of thalamocortical connections. Nature 347:179-181.

Grove EA, Tole S, Limon J, Yip L, Ragsdale CW (1998) The hem of the embryonic cerebral cortex is defined by the expression of multiple Wnt genes and is compromised in Gli3-deficient mice. Development 125:2315-2325

Grove EA, Fukuchi-Shimogori T (2003) Generating the cerebral cortical area map. Annu Rev Neurosci 26:355-380.

Guillery RW, Sherman SM (2002) Thalamic relay functions and their role in corticocortical communication: generalizations from the visual system. Neuron 33:163-175.

Hamasaki T, Leingartner A, Ringstedt T, O’Leary DD (2004) EMX2 regulates sizes and positioning of the primary sensory and motor areas in neocortex by direct specification of cortical progenitors. Neuron 43:359-372.

Hevner RF, Miyashita-Lin E, Rubenstein JL (2002) Cortical and thalamic axon pathfinding defects in Tbr1, Gbx2, and Pax6 mutant mice: evidence that cortical and thalamic axons interact and guide each other. J Comp Neurol 447:8-17.

Huffman KJ, Garel S, Rubenstein JL (2004) Fgf8 regulates the development of intra-neocortical projections. J Neurosci 24:8917-8923.

Inoue T, Tanaka T, Suzuki SC, Takeichi M (1998) Cadherin-6 in the developing mouse brain: expression along restricted connection systems and synaptic localization suggest a potential role in neuronal circuitry. Dev Dyn 211:338-351.

Iwasato T, Datwani A, Wolf AM, Nishiyama H, Taguchi Y, Tonegawa S, Knopfel T, Erzurumlu RS, Itohara S (2000) Cortex-restricted disruption of NMDAR1 impairs neuronal patterns in the barrel cortex. Nature 406:726-731.

Jeanmonod D, Rice FL, Van der Loos H (1981) Mouse somatosensory cor- 
tex: alterations in the barrelfield following receptor injury at different early postnatal ages. Neuroscience 6:1503-1535.

Kahn DM, Krubitzer L (2002) Massive cross-modal cortical plasticity and the emergence of a new cortical area in developmentally blind mammals. Proc Natl Acad Sci USA 99:11429-11434.

Kostovic I, Rakic P (1990) Developmental history of the transient subplate zone in the visual and somatosensory cortex of the macaque monkey and human brain. J Comp Neurol 297:441-470.

Lee SM, Tole S, Grove E, McMahon AP (2000) A local Wnt-3a signal is required for development of the mammalian hippocampus. Development 127:457-467.

Lopez-Bendito G, Molnar Z (2003) Thalamocortical development: how are we going to get there? Nat Rev Neurosci 4:276-289.

Lopez-Bendito G, Chan CH, Mallamaci A, Parnavelas J, Molnar Z (2002) Role of Emx2 in the development of the reciprocal connectivity between cortex and thalamus. J Comp Neurol 451:153-169.

Luskin MB, Shatz CJ (1985) Studies of the earliest generated cells of the cat's visual cortex: cogeneration of subplate and marginal zones. J Neurosci 5:1062-1075.

Ma L, Harada T, Harada C, Romero M, Hebert JM, McConnell SK, Parada LF (2002) Neurotrophin-3 is required for appropriate establishment of thalamocortical connections. Neuron 36:623-634.

Mackarehtschian K, Lau CK, Caras I, McConnell SK (1999) Regional differences in the developing cerebral cortex revealed by ephrin-A5 expression. Cereb Cortex 9:601-610.

Maier DL, Mani S, Donovan SL, Soppet D, Tessarollo L, McCasland JS, Meiri KF (1999) Disrupted cortical map and absence of cortical barrels in growth-associated protein (GAP)-43 knockout mice. Proc Natl Acad Sci USA 96:9397-9402.

Mallamaci A, Muzio L, Chan CH, Parnavelas J, Boncinelli E (2000) Area identity shifts in the early cerebral cortex of Emx2-/- mutant mice. Nat Neurosci 3:679-686.

McQuillen PS, DeFreitas MF, Zada G, Shatz CJ (2002) A novel role for p75 in subplate growth cone complexity and visual thalamocortical innervation. J Neurosci 22:3580-3593.

Miyashita-Lin EM, Hevner R, Wassarman KM, Martinez S, Rubenstein JL (1999) Early neocortical regionalization in the absence of thalamic innervation. Science 285:906-909.

Molnar Z, Adams R, Blakemore C (1998a) Mechanisms underlying the early establishment of thalamocortical connections in the rat. J Neurosci 18:5723-5745.

Molnar Z, Adams R, Goffinet AM, Blakemore C (1998b) The role of the first postmitotic cortical cells in the development of thalamocortical innervation in the reeler mouse. J Neurosci 18:5746-5765.

Molnar Z, Lopez-Bendito G, Small J, Partridge LD, Blakemore C, Wilson MC (2002) Normal development of embryonic thalamocortical connectivity in the absence of evoked synaptic activity. J Neurosci 22:10313-10323.

Muzio L, DiBenedetto B, Stoykova A, Boncinelli E, Gruss P, Mallamaci A (2002) Emx2 and Pax6 control regionalization of the pre-neuronogenic cortical primordium. Cereb Cortex 12:129-139.

Nakagawa Y, O'Leary DD (2001) Combinatorial expression patterns of LIM-homeodomain and other regulatory genes parcellate developing thalamus. J Neurosci 21:2711-2725.

Nakagawa Y, Johnson JE, O'Leary DD (1999) Graded and areal expression patterns of regulatory genes and cadherins in embryonic neocortex independent of thalamocortical input. J Neurosci 19:10877-10885.

Nauta WJH, Feirtag M (1986) Fundamental Neuroanatomy. New York: W.H. Freeman and Company.

O’Leary DD, Nakagawa Y (2002) Patterning centers, regulatory genes and extrinsic mechanisms controlling arealization of the neocortex. Curr Opin Neurobiol 12:14-25.
O’Leary DD, Schlaggar BL, Tuttle R (1994) Specification of neocortical areas and thalamocortical connections. Annu Rev Neuroscience 17:419-439.

Prakash N, Vanderhaeghen P, Cohen-Cory S, Frisen J, Flanagan JG, Frostig RD (2000) Malformation of the functional organization of somatosensory cortex in adult ephrin-A 5 knock-out mice revealed by in vivo functional imaging. J Neurosci 20:5841-5847.

Rakic P (1988) Specification of cerebral cortical areas. Science 241:170-176.

Rakic P, Suner I, Williams RW (1991) A novel cytoarchitectonic area induced experimentally within the primate visual cortex. Proc Natl Acad Sci USA 88:2083-2087.

Rubenstein JL, Anderson S, Shi L, Miyashita-Lin E, Bulfone A, Hevner R (1999) Genetic control of cortical regionalization and connectivity. Cereb Cortex 9:524-532.

Seibt J, Schuurmans C, Gradwhol G, Dehay C, Vanderhaeghen P, Guillemot F, Polleux F (2003) Neurogenin2 specifies the connectivity of thalamic neurons by controlling axon responsiveness to intermediate target cues. Neuron 39:439-452.

Sharma J, Angelucci A, Sur M (2000) Induction of visual orientation modules in auditory cortex. Nature 404:841-847.

Sherman SM, Guillery RW (2002) The role of the thalamus in the flow of information to the cortex. Philos Trans R Soc Lond B Biol Sci 357:1695-1708.

Soriano P (1999) Generalized lacZ expression with the ROSA26 Cre reporter strain. Nat Genet 21:70-71.

Sur M, Garraghty PE, Roe AW (1988) Experimentally induced visual projections into auditory thalamus and cortex. Science 242:1437-1441.

Sur M, Pallas SL, Roe AW (1990) Cross-modal plasticity in cortical development: differentiation and specification of sensory neocortex. Trends Neurosci 13:227-233.

Suzuki SC, Inoue T, Kimura Y, Tanaka T, Takeichi M (1997) Neuronal circuits are subdivided by differential expression of type-II classic cadherins in postnatal mouse brains. Mol Cell Neurosci 9:433-447.

Tabata H, Nakajima K (2001) Efficient in utero gene transfer system to the developing mouse brain using electroporation: visualization of neuronal migration in the developing cortex. Neuroscience 103:865-872.

Takemoto M, Fukuda T, Sonoda R, Murakami F, Tanaka H, Yamamoto N (2002) Ephrin-B3-EphA4 interactions regulate the growth of specific thalamocortical axon populations in vitro. Eur J Neurosci 16:1168-1172.

Uziel D, Muhlfriedel S, Zarbalis K, Wurst W, Levitt P, Bolz J (2002) Miswiring of limbic thalamocortical projections in the absence of ephrin-A5. J Neurosci 22:9352-9357.

Vanderhaeghen P, Lu Q, Prakash N, Frisen J, Walsh CA, Frostig RD, Flanagan JG (2000) A mapping label required for normal scale of body representation in the cortex. Nat Neurosci 3:358-365.

Van der Loos H, Woolsey TA (1973) Somatosensory cortex: structural alterations following early injury to sense organs. Science 179:395-398.

Vigers AJ, Baquet ZC, Jones KR (2000) Expression of neurotrophin-3 in the mouse forebrain: insights from a targeted LacZ reporter. J Comp Neurol 416:398-415

Woolsey TA, Van der Loos H (1970) The structural organization of layer IV in the somatosensory region (SI) of mouse cerebral cortex. The description of a cortical field composed of discrete cytoarchitectonic units. Brain Res 17:205-242.

Yasuda K, Momose T, Takahashi Y (2000) Applications of microelectroporation for studies of chick embryogenesis. Dev Growth Differ 42:203-206.

Yun ME, Johnson RR, Antic A, Donoghue MJ (2003) EphA family gene expression in the developing mouse neocortex: regional patterns reveal intrinsic programs and extrinsic influence. J Comp Neurol 456:203-216.

Zhou FC, Sari Y, Zhang JK (2000) Expression of serotonin transporter protein in developing rat brain. Brain Res Dev Brain Res 119:33-45. 